\title{
Correction: Superior survival with pediatric-style chemotherapy compared to myeloablative allogeneic hematopoietic cell transplantation in older adolescents and young adults with $\mathrm{Ph}$-negative acute lymphoblastic leukemia in first complete remission: analysis from CALGB 10403 and the CIBMTR
}

Matthew J. Wieduwilt (D) - Wendy Stock • Anjali Advani (D) - Selina Luger (D) Richard A. Larson (D) Martin Tallman • Frederick Appelbaum • Mei-Jie Zhang • Khalid Bo-Subait • Hai-Lin Wang • Vijaya Raj Bhatt (D) Bhagirathbhai Dholaria (D) Mary Eapen • Mehdi Hamadani $(\mathbb{D} \cdot$ Omer Jamy • Tim Prestidge (D) Michael Pulsipher (D) David Ritchie - David Rizzieri - Akshay Sharma (D) Pere Barba (D) Brenda M. Sandmaier Marcos de Lima $(\mathbb{D} \cdot$ Partow Kebriaei (D) Mark Litzow $($ Dael Saber - Daniel Weisdorf (D)

Published online: 4 June 2021

(c) The Author(s), under exclusive licence to Springer Nature Limited 2021

Correction to: Leukemia

https://doi.org/10.1038/s41375-021-01213-5

The article requires a correction in the funding/acknowledgement statement used. There is a grant number
(OT3HL147741) in the "Acknowledgments" section that needs to be removed.

The original publication was updated. 